\title{
Removal of aromatic inhibitors produced from lignocellulosic hydrolysates by Acinetobacter baylyi ADP1 with formation of ethanol by Kluyveromyces marxianus
}

\author{
Anita Singh ${ }^{1,2}$, Stacy R. Bedore ${ }^{3}$, Nilesh K. Sharma², Sarah A. Lee ${ }^{2}$, Mark A. Eiteman ${ }^{1,2^{*}}$ (i) and Ellen L. Neidle ${ }^{3}$
}

\begin{abstract}
Background: Lignocellulosic biomass is an attractive, inexpensive source of potentially fermentable sugars. However, hydrolysis of lignocellulose results in a complex mixture containing microbial inhibitors at variable composition. A single microbial species is unable to detoxify or even tolerate these non-sugar components while converting the sugar mixtures effectively to a product of interest. Often multiple substrates are metabolized sequentially because of microbial regulatory mechanisms. To overcome these problems, we engineered strains of Acinetobacter baylyi ADP1 to comprise a consortium able to degrade benzoate and 4-hydroxybenzoate simultaneously under batch and continuous conditions in the presence of sugars. We furthermore used a thermotolerant yeast, Kluyveromyces marxianus, to convert the glucose remaining after detoxification to ethanol.
\end{abstract}

Results: The two engineered strains, one unable to metabolize benzoate and another unable to metabolize 4-hydroxybenzoate, when grown together removed these two inhibitors simultaneously under batch conditions. Under continuous conditions, a single strain with a deletion in the gcd gene metabolized both inhibitors in the presence of sugars. After this batch detoxification using ADP1-derived mutants, K. marxianus generated $36.6 \mathrm{~g} / \mathrm{L}$ ethanol.

Conclusions: We demonstrated approaches for the simultaneous removal of two aromatic inhibitors from a simulated lignocellulosic hydrolysate. A two-stage batch process converted the residual sugar into a non-growth-associated product, ethanol. Such a two-stage process with bacteria (A. baylyi) and yeast (K. marxianus) is advantageous, because the yeast fermentation occurs at a higher temperature which prevents growth and ethanol consumption of A. baylyi. Conceptually, the process can be extended to other inhibitors or sugars found in real hydrolysates. That is, additional strains which degrade components of lignocellulosic hydrolysates could be made substrate-selective and targeted for use with specific complex mixtures found in a hydrolysate.

Keywords: Acinetobacter baylyi, Detoxification, Ethanol, Kluyveromyces marxianus, Microbial consortium

\section{Introduction}

Lignocellulosic biomass represents an underutilized renewable resource readily available from forestry and agricultural residues. For example, about $60 \%$ of United States logging residue and forest thinning materials can be harvested, totaling 75 million tons annually [52].

\footnotetext{
*Correspondence: eiteman@engr.uga.edu

${ }^{2}$ School of Chemical, Materials and Biomedical Engineering, University

of Georgia, Athens, GA 30602, USA

Full list of author information is available at the end of the article
}

Corn is the most widely planted agricultural crop in the U.S., and estimated 40 million tons of corn stover are sustainably available for bio-based products [20]. Promising "energy crops" have also been identified, such as switchgrass, Napier grass and Miscanthus that provide high yield/energy content require low maintenance, often grow on marginal lands, and do not divert food to fuel. The annual global production rate of potentially accessible primary biomass is $8-20 \times 10^{9}$ tons [39], and this material is of interest for the production of liquid 
transportation fuels through chemical [16] or biological routes [12]. Estimated 400-600 billion liters of ethanol could be generated from these lignocellulosic crops, residues, and waste [23, 36, 41]. Agricultural residues from corn, wheat, rice, and sugarcane crops are particularly appealing, since they are distributed throughout the populous world.

Biomass is an attractive feedstock for the biochemical production of fuels and chemicals using a microbial conversion platform. However, such conversions encounter two significant challenges. First, although the large available volume and cost of biomass align well with the production of commodity chemicals such as ethanol, the variability of these feedstocks is problematic for microbial metabolism. Even a single feedstock can vary substantially: for example, in one study, corn stover contained $0.9-2.9 \%$ acetyl groups, $26-38 \%$ glucans, and $15-23 \%$ xylans on a whole biomass basis [47]. Similarly, cotton gin residue varied between 3 and 13\% xylans and 20-38\% glucans, with the composition dependent on the day of collection [1]. A microbial process ideally should be able to tolerate the inherent variability of the biomass feedstock.

The second major challenge for bioconversion processes is that methods used to liberate sugars involve high heat and pressure with acids/bases that generate microbial inhibitors such as acetic acid [25, 31, 38, 48], furans [14], and aromatic compounds [28, 49, 50]. The concentrations of these compounds depend on the biomass feedstock and the hydrolysis process. For example, using $4 \%$ phosphoric acid to hydrolyze sugarcane bagasse at $122{ }^{\circ} \mathrm{C}$ generated $3 \mathrm{~g} / \mathrm{L}$ acetic acid and $0.6 \mathrm{~g} / \mathrm{L}$ furfural [11], while hydrolysis of corn stover using dilute sulfuric acid with a short residence time and $200{ }^{\circ} \mathrm{C}$ generated $14 \mathrm{~g} / \mathrm{L}$ acetic acid and $5 \mathrm{~g} / \mathrm{L}$ furfural [6]. Thus, in addition to the inherent variability of sugar in the feedstocks, pre-treatment methods generate variation in the inhibitory mixtures. Despite progress, many difficulties remain in the microbial conversion of lignocellulose to fuels and chemicals, in particular the presence of the numerous inhibitors in hydrolysates and their variable composition $[3,45]$.

A single microbial species has not been identified that can detoxify or even tolerate the non-sugar components of lignocellulose hydrolysates while effectively converting the sugar mixtures to a product of interest. An alternative to the use of a single microbe is the use of a microbial consortium for detoxification and biochemical conversion of the sugars [9]. For example, the sugars glucose, xylose, and arabinose as well as the inhibitor acetic acid can be degraded simultaneously by a consortium of different Escherichia coli strains [55]. As an extension of this approach, inhibitors could be removed in a first stage, followed by a second process targeting bioconversion of the remaining sugar mixture. Each stage of such a twostage process could itself be comprised of a microbial consortium, with members each carrying out a specific detoxification or conversion. The increasing interest and applications of microbial consortia have been reviewed [54].

Alkaline pre-treatment of biomass yields a hydrolysate stream-containing numerous aromatic acids such as vanillic acid, ferulic acid, and 4-hydroxybenzoic acid [22] Although a few biochemical production strains tolerate significant quantities of these inhibitors, several strains of Amycolatopsis, Pseudomonas putida, Acinetobacter baylyi, and Rhodococcus jostii metabolize many lowmolecular-weight compounds normally considered to be inhibitors [40]. These bacteria represent good hosts for engineering towards the removal of inhibitors. A. baylyi ADP1 additionally possesses a highly efficient system for natural transformation and chromosomal incorporation of exogenous DNA [10,57]. This genetic malleability facilitates the generation of mutants with specific chromosomal changes and also the evolution of new enzymes for lignin valorization [51]. In ADP1, an engineered deletion of $g c d$, a gene-encoding glucose dehydrogenase, fails to metabolize glucose, xylose, or arabinose. Furthermore, this strain metabolizes acetate, formate, and 4-hydroxybenzoate (4HB) simultaneously in the absence of glucose, or, when glucose is present, it degrades acetate and formate [21]. The $g c d$ mutant also grows aerobically on citrate in an enzymatic rice straw hydrolysate prior to anaerobic growth of Clostridium butyricum for the production of hydrogen gas [21].

In this study, we used a consortium of ADP1-derived strains to metabolize both benzoate and $4 \mathrm{HB}$ as a model detoxification step prior to the conversion of glucose to ethanol by Kluyveromyces marxianus [2]. Because the optimal growth and fermentation conditions for this yeast are unfavorable to bacterial growth $\left(42^{\circ} \mathrm{C}\right.$ and a pH less than 5.5), $K$. marxianus is uniquely suited to a twostage process that requires bacterial inactivation in the second stage.

\section{Results and discussion}

\section{Selective consumption of aromatic compounds}

Acinetobacter baylyi ADP1 consumes benzoate and $4 \mathrm{HB}$ by converting them to central metabolites (acetyl $\mathrm{CoA}$ and succinyl $\mathrm{CoA}$ ) via the catechol and protocatechuate branches, respectively, of the $\beta$-ketoadipate pathway (Fig. 1). When both compounds are present, ADP1 metabolizes them sequentially: $4 \mathrm{HB}$ consumption commences only when most of the benzoate is depleted [4]. 
We hypothesized that both benzoate and $4 \mathrm{HB}$ could be simultaneously consumed by a consortium of two different ADP1-derived mutants, one of which would consume only benzoate and another that would consume only $4 \mathrm{HB}$. The strain that consumes $4 \mathrm{HB}$ could be prevented from degrading benzoate by inactivating a gene needed for catechol formation. An analogous mutant blocked in the protocatechuate branch of the pathway could consume benzoate. More generally, a consortium of specifically engineered mutants might consume different aromatic compounds in a mixture regardless of the composition of the hydrolysate.

In an ADP1-derived mutant, ACN462, the deletion of the pcaGH genes, which encode protocatechuate 3,4-dioxygenase, prevented catabolism of protocatechuate and thereby also 4HB. ACN462 consumed $2 \mathrm{mM}$ benzoate as the sole carbon source in less than $8 \mathrm{~h}$ yielding an OD of about 0.35 (Fig. 2a). When ACN462 was grown in the same medium that additionally contained $5 \mathrm{mM} 4 \mathrm{HB}$, there was no change in benzoate metabolism or cell yield, suggesting that $4 \mathrm{HB}$ had no inhibitory effect (Fig. 2b). A different ADP1-derived mutant, ACN472, was unable to consume benzoate because of the deletion of benD, which encodes the dehydrogenase needed for the conversion of benzoate to catechol. ACN472 depleted $5 \mathrm{mM} 4 \mathrm{HB}$ as the sole carbon source in $5 \mathrm{~h}$ (Fig. 3a). When the same medium additionally contained $2 \mathrm{mM}$ benzoate, ACN472 exclusively metabolized $4 \mathrm{HB}$ within $8 \mathrm{~h}$ (Fig. $3 \mathrm{~b}$ ). The deletion of the pcaGH and benD genes in separate ADP1-derived strains resulted in one strain that only consumed benzoate (ACN462) and one that only consumed 4HB (ACN472) when provided with both aromatic substrates.

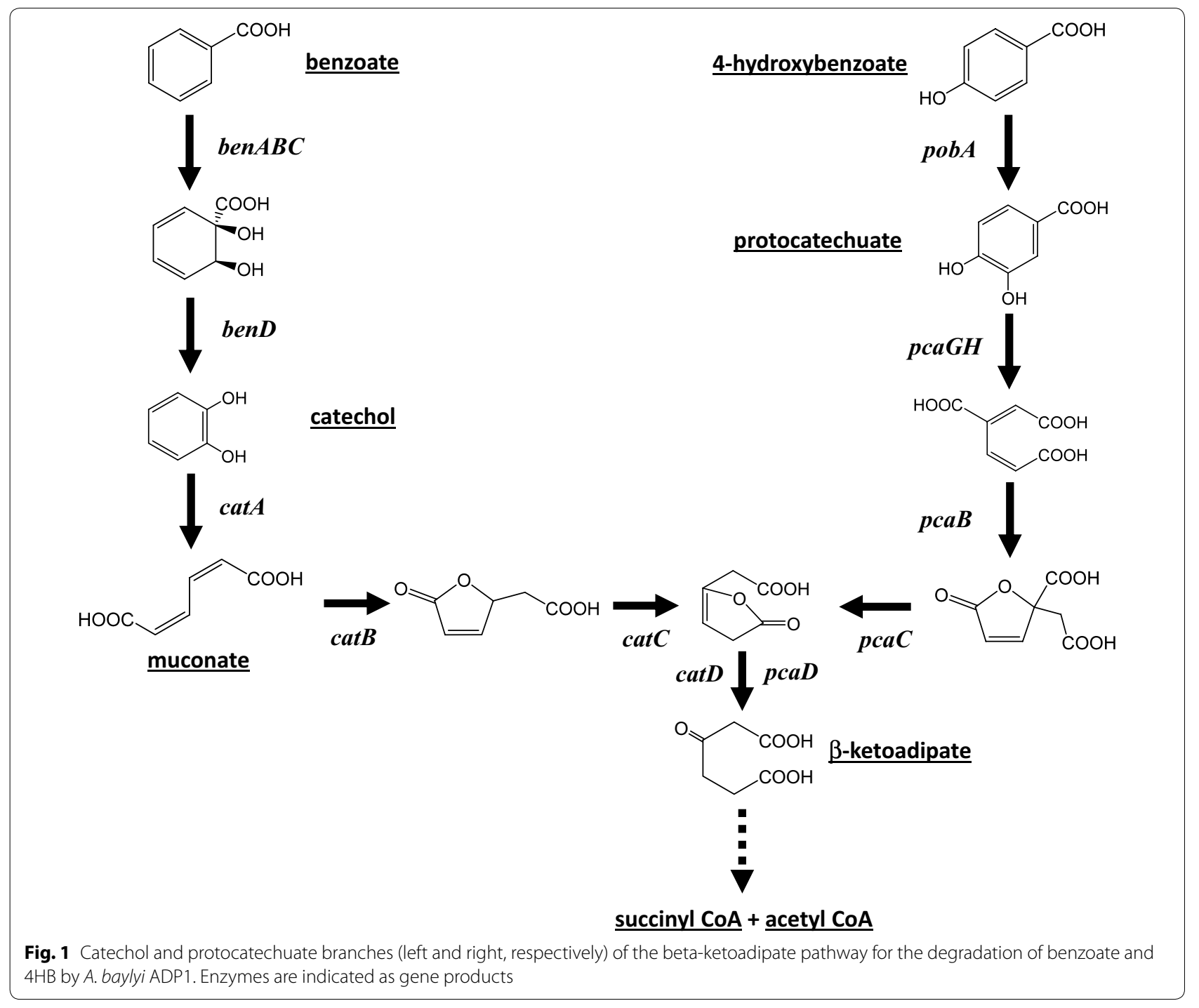



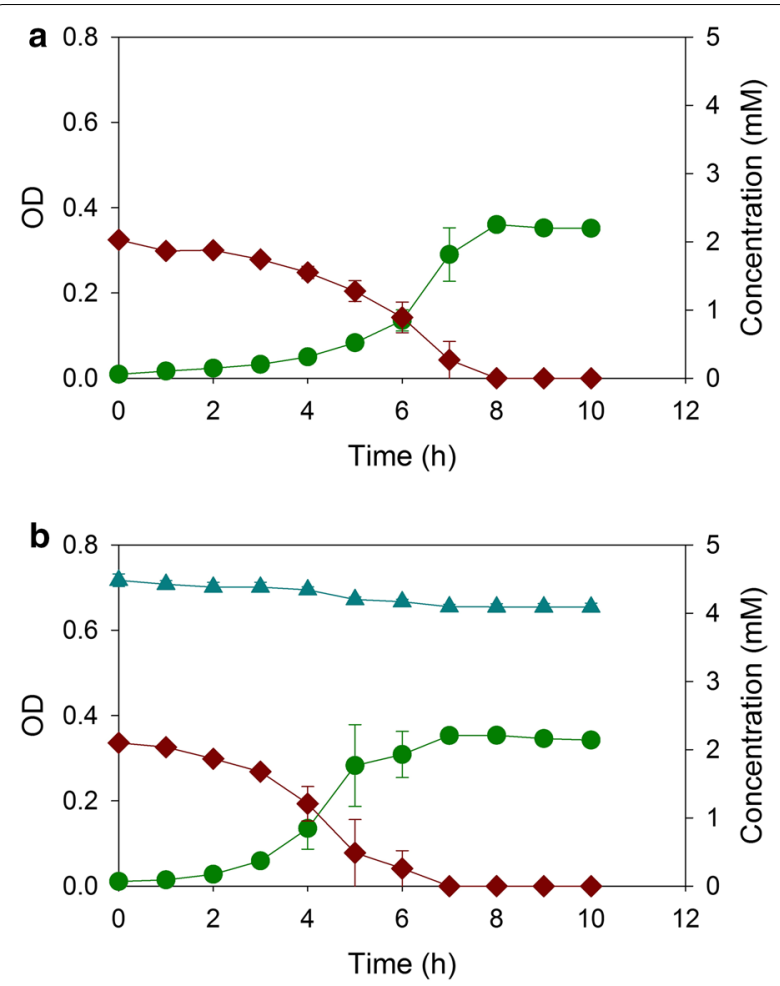

Fig. 2 Growth of ACN462 on $\mathbf{a}$ benzoate and $\mathbf{b}$ benzoate and 4-hydroxybenzoate: OD (dark green circle), benzoate (brown diamond), and 4-hydroxybenzoate (blue up pointing triangle). Error bars represent standard error of the mean

\section{Selective growth in the presence of sugars}

Real hydrolysates contain sugars, which, generally, are poor growth substrates for ADP1. This bacterium is unable to metabolize xylose or arabinose, and its utilization of glucose can be prevented by deletion of the $g c d$ gene [21]. A. baylyi strains were next constructed to prevent the consumption of glucose during the selective degradation of aromatic compounds. One mutant, designated ACN2090, was engineered to carry two deletions, $\Delta p c a G H$ and $\Delta g c d$. Another mutant, designated ACN2091, was engineered to carry $\Delta b e n D$ and $\Delta g c d$. In a mixture of glucose, xylose, arabinose, $4 \mathrm{HB}$, and benzoate, ACN2090 exhausted $2 \mathrm{mM}$ benzoate within $7 \mathrm{~h}$ (Fig. 4a), and ACN2091 consumed $5 \mathrm{mM} 4 \mathrm{HB}$ within $9 \mathrm{~h}$ (Fig. 4b). These two substrate-selective strains were largely unaffected by the presence of glucose, xylose, and arabinose.

We next tested metabolism by a consortium of both strains, ACN2090 and ACN2091. When provided with a mixture of sugars and aromatic compounds, this consortium simultaneously metabolized both benzoate and $4 \mathrm{HB}$ within $8 \mathrm{~h}$ (Fig. 5). In contrast to the fashion in which benzoate and $4 \mathrm{HB}$ are consumed by the wild-type strain (ADP1), we observed no delay in the commencement of $4 \mathrm{HB}$ degradation. Each strain in the presence of two carbon sources behaved the same as in the presence of the single carbon source (i.e., Fig. 2a, b).

\section{Growth in continuous culture}

The studies described so far were completed under batch conditions in which the bacteria initially experience an excess of the carbon source(s). We sought to compare these results using a batch culture to the behavior of strains in a chemostat whereby a nutrient feed is supplied continuously at a constant rate, and an effluent from the bioreactor is withdrawn at the same rate resulting in a constant volume bioreactor. At the initiation of such a process, cell density increases until one (limiting) nutrient is depleted, and a steady-state is achieved. If the carbon sources are limiting, then the steady-state concentrations of those substrates would be very low throughout the process. Under these conditions, cells often are able to consume multiple substrates simultaneously and avoid the diauxie that is observed during batch growth [13]. Moreover, changes in the feed composition of the limiting nutrients should affect only the cell density and not the effluent concentration of the limiting nutrients (as long as they remain limiting). Thus, a variable composition but constant-flowrate feed introduced into a "chemostat" would tend to maintain a single effluent composition. As a general practice, such a process would not only generate a consistent effluent for a subsequent process, but it can also maintain that stability when confronted with a variable composition feed such as those that might be encountered in lignocellulosic hydrolysates.

Under carbon limitation, we expected $A$. baylyi to consume benzoate and $4 \mathrm{HB}$ simultaneously. To prevent glucose catabolism in an otherwise wild-type strain, we constructed ACN2069 $(\Delta g c d)$. This single strain could then be used to consume mixtures of aromatic compounds and sugars. ACN2069 was grown in a chemostat to degrade both benzoate and $4 \mathrm{HB}$ using a constant dilution rate of $0.2 \mathrm{~h}^{-1}$. To examine the robustness of this continuous process, the feed composition (but not flowrate) was shifted every $24 \mathrm{~h}$ : at the onset, the nominal composition was $2 \mathrm{mM}$ benzoate and $5 \mathrm{mM} 4 \mathrm{HB}$; at $24 \mathrm{~h}$ benzoate shifted to $5 \mathrm{mM}$; at $48 \mathrm{~h}$, the feed contained $10 \mathrm{mM} \mathrm{4HB}$; and then, finally at $72 \mathrm{~h}$, the feed shifted to $2 \mathrm{mM}$ benzoate. Throughout the process, the influent concentration of sugars remained nominally $10 \mathrm{mM}$ glucose, $10 \mathrm{mM}$ xylose, and $10 \mathrm{mM}$ arabinose. The system was allowed about five residence times during each feed, so that a steady-state would essentially be achieved for that feed composition. Figure 6 shows the results of this $96 \mathrm{~h}$ process. The system maintained a negligible effluent concentration of benzoate and $4 \mathrm{HB}$, despite the shifting feed composition. 

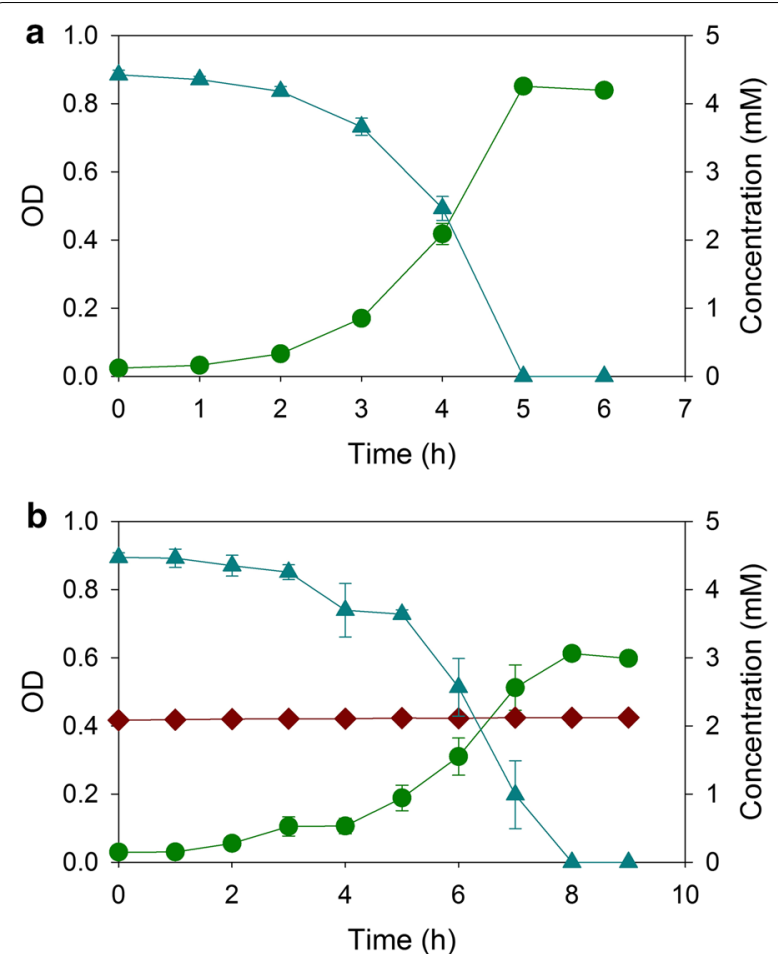

Fig. 3 Growth of ACN472 on a 4-hydroxybenzoate and $\mathbf{b}$ benzoate and 4-hydroxybenzoate: OD (dark green circle), benzoate (brown diamond), 4-hydroxybenzoate (blue up pointing triangle). Error bars represent standard error of the mean

The cell density increased or decreased in proportion to the total quantity of metabolizable carbon/energy sources. During the process, the concentration of the three sugars remained at $10 \mathrm{mM}$, demonstrating that they were not consumed over the course of the 4 days, and that glucose-degrading mutants did not arise spontaneously [5]. Since the strains never encountered high and potentially toxic concentrations of the aromatic substrates, such a continuous process using substrateselective microbes would be a very effective means to remove a portion of the carbon sources from a variable feed stream.

\section{Removal of inhibitors and formation of a biochemical product}

The results suggest that a two-stage microbial process could be developed to (1) detoxify an inhibitor-containing feed stream and (2) convert the resulting sugar stream into a biochemical product. Such a process might employ any of several operational modes. For example, a consortium of inhibitor-consuming microbes could remove multiple components during a batch culture, with each microbe simultaneously degrading one target compound (i.e., Fig. 5). Subsequently, after the depletion of inhibitors, one or more microbes could be introduced into the same batch to convert the remaining sugars into a desired biochemical product, such as ethanol. Alternatively, a continuous process could be developed whereby the inhibitors are removed in one bioreactor, and in a separate, second reactor the sugars are converted into a product. Each stage of such a two-stage process could involve a different microbial species and different environmental conditions. An example of an envisioned continuous process is shown in Fig. 7, where appropriate strain(s) are introduced into a second reactor to convert the sugar mixture into a product. In each reactor of this "fully continuous" configuration, the microbes must be growing, and thus, the product must be a growth-associated product such as pyruvate [26]. One critical aspect of implementing a two-stage detoxification/conversion process using any operational mode is that the first inhibitorconsuming microbe(s) must be unable to metabolize the product under the environmental conditions found in the second stage. This goal could be accomplished by deleting catabolic routes in the strain(s) used for detoxification, or by operating the second stage in an environment unfavorable to the growth of the first-stage detoxification microbes. An advantage of such a two-stage process, in contrast to simultaneous degradation and conversion, is that the environmental conditions for each stage (medium, temperature, $\mathrm{pH}$, etc.) can be independently optimized.

To demonstrate a two-stage biological process to detoxify a stream and generate a product, we set up the first stage as a batch process to remove benzoate and $4 \mathrm{HB}$ using two strains of A. baylyi. For the second production stage, Kluyveromyces marxianus was then used in the same reactor to convert the remaining sugar, glucose, into ethanol. Like many other microbes, we determined that the growth of $K$. marxianus was inhibited by $2.5 \mathrm{mM}$ benzoate (data not shown). Although ADP1 is able to metabolize ethanol [46], $K$. marxianus grows at $42{ }^{\circ} \mathrm{C}$ and a pH of 5.0-5.5 [24,37], conditions at which ADP1 will neither grow nor metabolize ethanol. After $4 \mathrm{HB}$ and benzoate in the initial batch were depleted, a more concentrated mixture of $4 \mathrm{HB}$ and benzoate was slowly introduced. After the degradation of the inhibitors, the temperature was increased and the $\mathrm{pH}$ lowered to eliminate active $A$. baylyi cells. Before the introduction of the yeast, the temperature was adjusted to operating conditions suitable for the yeast $\left(42^{\circ} \mathrm{C}\right.$ and $\mathrm{pH}$ of 5.2).

The $1.0 \mathrm{~L}$ batch process began with a reactor containing nominally $100 \mathrm{~g} / \mathrm{L}$ glucose, $5 \mathrm{mM} 4 \mathrm{HB}$, and $2.5 \mathrm{mM}$ benzoate (results are shown in Fig. 8). After $9.7 \mathrm{~h}$, both aromatic carbon sources were depleted by ACN2090 and ACN2091, and a feed of $100 \mathrm{~g} / \mathrm{L}$ glucose, $11 \mathrm{mM} 4 \mathrm{HB}$, 

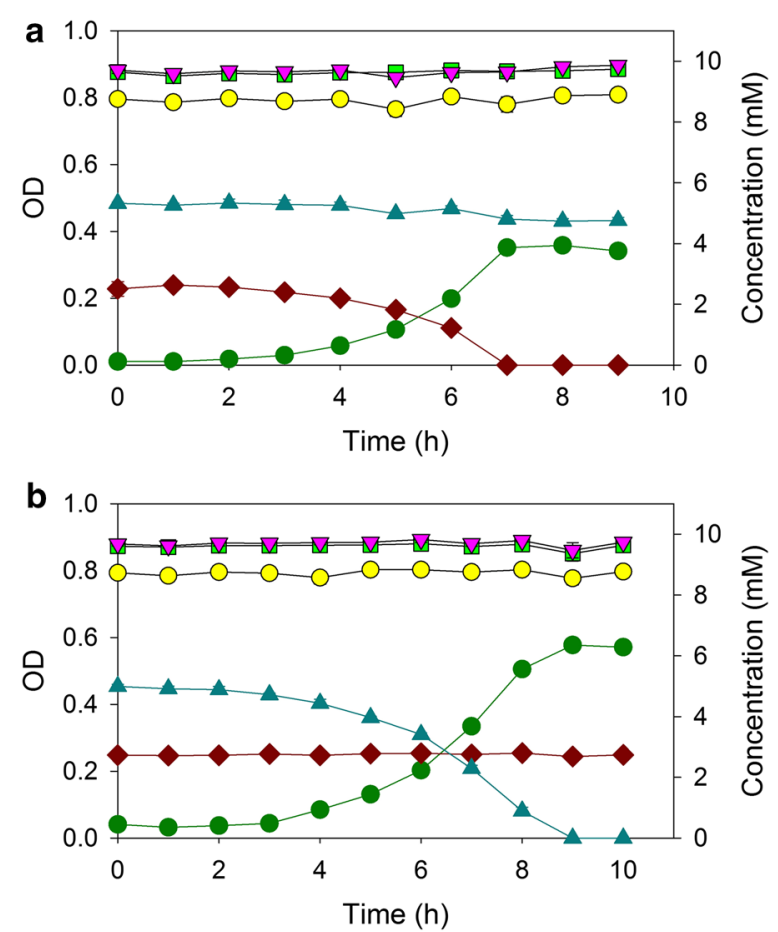

Fig. 4 Growth of a ACN2090 and b ACN2091 on mixtures of benzoate, 4-hydroxybenzoate, glucose, xylose, and arabinose: OD (dark green circle), benzoate (brown diamond), 4-hydroxybenzoate (blue up pointing triangle), glucose (yellow circle), xylose (light green square), and arabinose (pink down pointing triangle). Error bars represent standard error of the mean

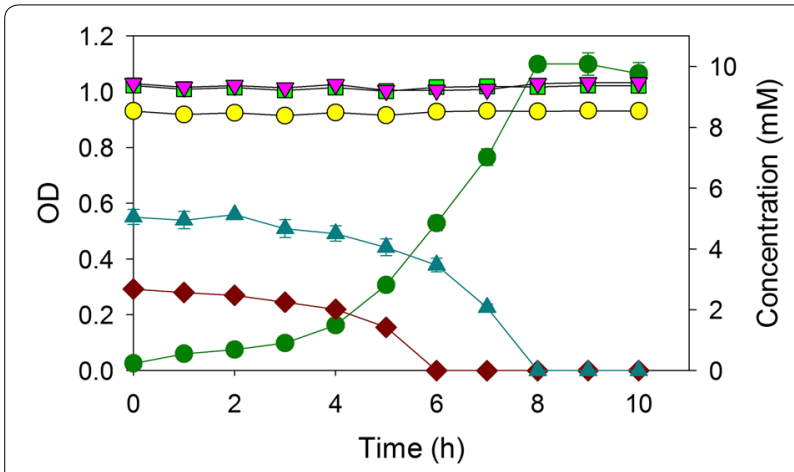

Fig. 5 Growth of ACN2090 and ACN2091 together on a mixture of benzoate, 4-hydroxybenzoate, glucose, xylose, and arabinose: OD (dark green circle), benzoate (brown diamond), 4-hydroxybenzoate (blue up pointing triangle), glucose (yellow circle), xylose (light green square), and arabinose (pink down pointing triangle). Error bars represent standard error of the mean

and $6 \mathrm{mM}$ benzoate was introduced at a constant flowrate of $1 \mathrm{~mL} / \mathrm{min}$ (corresponding to an initial dilution rate of $0.06 \mathrm{~h}^{-1}$ ), resulting in an increase of the bioreactor volume to approximately $1.6 \mathrm{~L}$ after an additional $9.8 \mathrm{~h}$.
The feed was terminated, the temperature was raised to $55^{\circ} \mathrm{C}$ and the $\mathrm{pH}$ lowered to 4.3 , and finally, the temperature was quickly lowered to $42{ }^{\circ} \mathrm{C}$ and the $\mathrm{pH}$ increased to 5.2 (the heating, holding and cooling cycle required $3.5 \mathrm{~h})$. After inoculation with $K$. marxianus, aerobic conditions were provided for $9.3 \mathrm{~h}$ before switching to anaerobic conditions for the final $17.5 \mathrm{~h}$. Similar to shake flask studies using a microbial consortium (Fig. 5), the initial 4HB and benzoate were consumed simultaneously (Fig. 8). Although the feed contained $4 \mathrm{HB}$ and benzoate at over twice the concentration present at the onset of the batch phase, the system maintained a zero concentration of aromatics during that portion of the process. This result demonstrates benefits of a continuous process: the presence of active cells during the feeding period, and the dilution effect achieved by introducing a concentrated feed into a larger dilute reservoir, result in a negligible concentration of the inhibitors. During the anaerobic phase $(21.3 \mathrm{~h}-49 \mathrm{~h}), 36.6 \mathrm{~g} / \mathrm{L}$ ethanol was generated at a yield of $0.38 \mathrm{~g} / \mathrm{g}$ glucose (Fig. 8).

In this study, we described approaches (using a single strain or two substrate-selective strains, as necessary) to remove two aromatic hydrocarbons simultaneously from a simulated lignocellulosic hydrolysate. We also demonstrated the degradation of two aromatic hydrocarbons followed by the conversion of a residual sugar into ethanol. In this case, a two-stage batch process was used, because the product, ethanol, is a non-growthassociated product. A continuous process allowing for high volumetric productivity would be advantageous for growth-associated products, in which case the dilution rates of each stage (and vessel) can be independently established. Conceptually, the process can be extended to other inhibitors or sugars found in real hydrolysates. That is, additional strains which degrade components of lignocellulosic hydrolysate can be made substrate-selective and introduced into the complex mixture found in a hydrolysate.

The proposed microbial consortium process provides another approach to the wide range of biological, physical, and chemical methods studied for the detoxification of lignocellulosic hydrolysates [29, 30]. In addition to the selective removal of specific compounds described in this study, biological methods for addressing inhibition include the use of enzyme laccase and peroxidase enzymes [18] or fungi directly [33,59], the use of a coculture of detoxifying and fermenting microbes [58], and the adaptation of strains to hydrolysates [42, 44]. More prevalent are physical and chemical methods including over-liming [27], adsorption on activated charcoal [35] or ion-exchange [34]. The use of a consortium of substrate-selective microbes has the advantages of being well aligned with the equipment and culture requirements of 


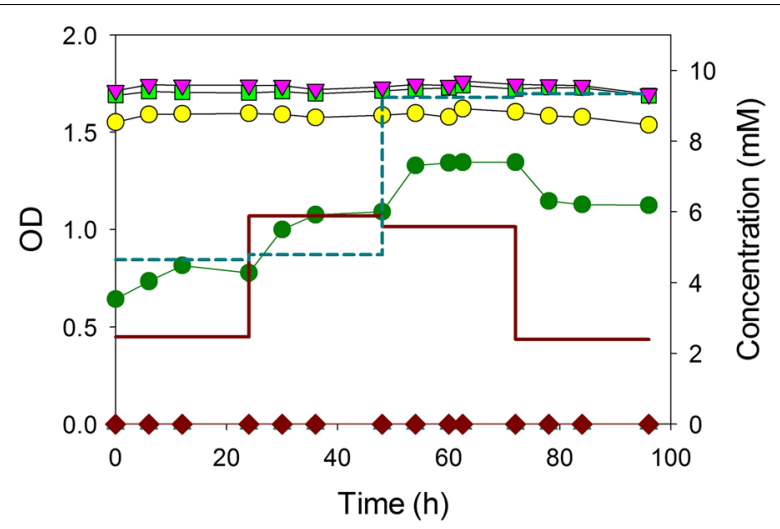

Fig. 6 Growth of ACN2069 in continuous chemostat culture: OD (dark green circle), benzoate (brown diamond), 4-hydroxybenzoate (blue up pointing triangle), glucose (yellow circle), xylose (light green square), and arabinose (pink down pointing triangle). The feed concentrations (each) of glucose, xylose, and arabinose were maintained at nominally $10 \mathrm{mM}$, and the concentrations of benzoate (brown straight line) and 4-hydroxybenzoate (blue dashed lines) were step-changed approximately every $24 \mathrm{~h}$ as described in "Materials and methods"

a subsequent bioconversion step, and being amenable to the variability of the hydrolysate.

\section{Materials and methods}

\section{Strains and plasmids}

Bacterial strains were derived from $A$. baylyi ADP1 (Table 1). Chromosomal mutations were engineered via allelic replacement with linearized plasmids that transformed naturally competent $A$. baylyi hosts, as previously described [32]. Each new strain is a transformant in which a plasmid-borne allele replaced the corresponding chromosomal locus. The genotypes of new strains were confirmed by PCR and regional DNA sequencing.

Plasmids are shown in Table 2. To construct strains unable to degrade glucose, two plasmids were made with a defined deletion of $g c d$ (locus designation ACIAD_RS13470, or ACIAD2983, at position $2,911,967 \leftarrow 2,914,372$, in the ADP1 genome, NC_005966 in NCBI). One of these plasmids, pBAC1565, carries ADP1 DNA surrounding gcd from genomic positions 2,909,747 (downstream of $g c d$ ) to 2,916,396 (upstream of $g c d$ ). In this region, the coding sequence of $g c d$ was deleted (except for the translational start and stop signals). The deletion corresponds to genome positions $2,911,970-2,914,369$. In place of the deleted DNA, a BamHI recognition sequence (GGATCC) was inserted. This plasmid was constructed by joining two PCR products using splicing by overlap extension PCR (SOEing) [15]. One PCR product was generated with primers SRB36 and SRB38 and the other with SRB39 and SRB37 (Additional file 1: Table S1). The joined SOEing fragment (made with primers SRB39 and SRB38) was ligated into the cloning vector pUC18 after restriction digestion with PstI and Eco53KI. The second plasmid carrying a gcd deletion, pBAC1566, was created to carry a selectable/ counter-selectable marker inserted into the engineered BamHI site of pBAC1565, within the deleted gcd region. This marker, a $s a c B-\mathrm{Km}^{\mathrm{R}}$ cassette, was excised from pRMJ1 [17].

Three strains were constructed in which $g c d$ was deleted and replaced with the $s a c B-\mathrm{Km}^{\mathrm{R}}$ cassette (allele $\Delta$ gcd::sacB-Km $\left.{ }^{\mathrm{R}} 52069\right): \quad \mathrm{ACN} 2069, \quad \mathrm{ACN} 2070$, and ACN2071. These strains were selected by resistance to kanamycin $(\mathrm{Km})$ after linearized pBAC1566 transformed three recipient strains, ADP1, ACN462, and ACN472,

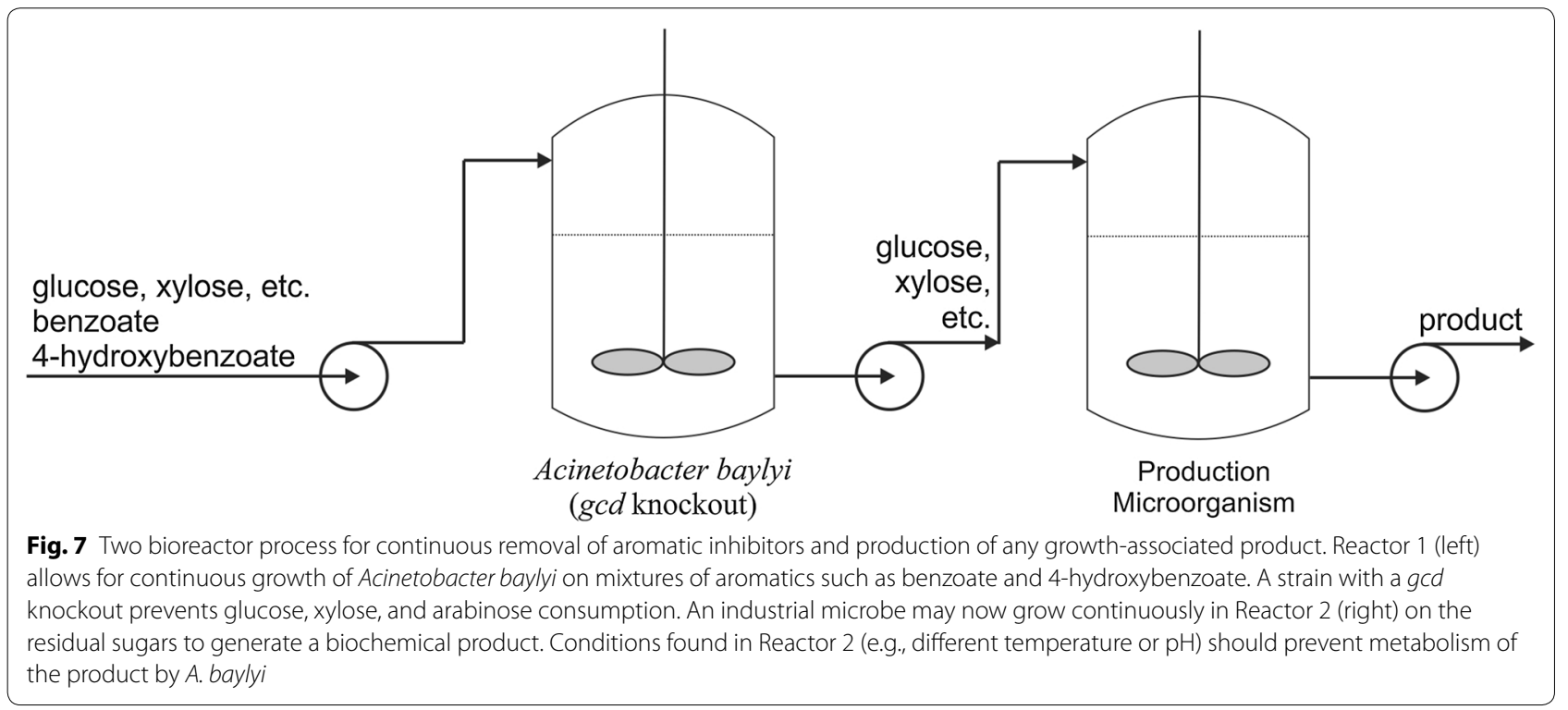



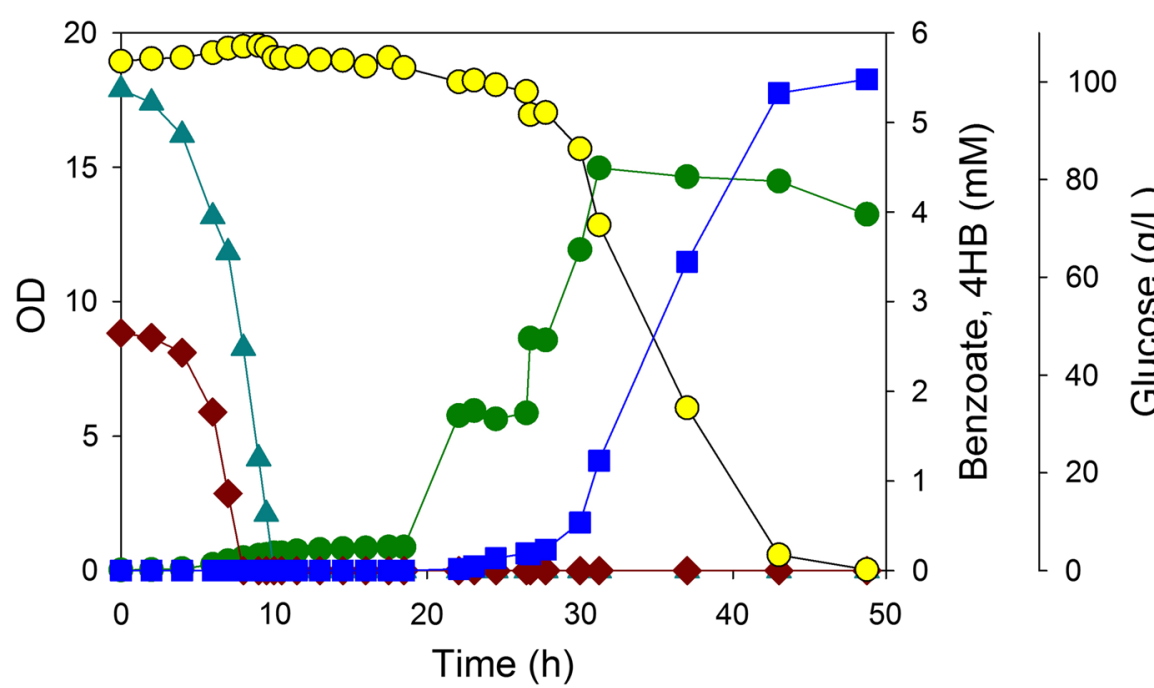

$[40$

30

30

\section{흥}

20

을

10

$\frac{1}{\frac{1}{0}}$

Time (h)

Fig. 8 Two-stage process for the degradation of benzoate (brown diamond) and 4HB (blue up pointing triangle) in a mixture with glucose (yellow circle) and the subsequent conversion to ethanol (blue square). The total bacterial + yeast OD (dark green circle). ACN2090 and ACN2091 were inoculated into a mixture of $100 \mathrm{~g} / \mathrm{L}$ glucose, $5 \mathrm{mM} 4 \mathrm{HB}$, and $2.5 \mathrm{mM}$ benzoate. After $9.7 \mathrm{~h}$, both aromatic carbon sources were depleted, and a feed of $100 \mathrm{~g} / \mathrm{L}$ glucose, $11 \mathrm{mM} 4 \mathrm{HB}$, and $6 \mathrm{mM}$ benzoate was introduced at a constant flowrate of $1 \mathrm{~mL} / \mathrm{min}$ (an initial dilution rate of $0.06 \mathrm{~h}^{-1}$ ), resulting in an increase of the bioreactor volume to approximately $1.6 \mathrm{~L}$ after an additional $9.8 \mathrm{~h}$. After this feed was terminated, the temperature was raised to $55^{\circ} \mathrm{C}$ and the $\mathrm{pH}$ lowered to 4.3 , and then, the temperature quickly lowered to $42^{\circ} \mathrm{C}$ and the $\mathrm{pH}$ increased to 5.2 (the complete cycle required $3.5 \mathrm{~h}$ ). After inoculation with K. marxianus, aerobic conditions were provided for $9.3 \mathrm{~h}$ before switching to anaerobic conditions for the final $17.5 \mathrm{~h}$

Table 1 Acinetobacter baylyi strains used in this study

\begin{tabular}{|c|c|c|}
\hline Strain & Relevant characteristics & Sources \\
\hline ADP1 & Wild type (BD413) & Juni and Janik [19] \\
\hline ACN462 & $\begin{array}{l}\triangle \text { pcaHG5462 } \\
\text { Deletion of DNA from 1,717,153 to 1,715,814a replaced with GCGGCCGC, the recognition } \\
\text { sequence for Notl } \\
\text { PCR fragment X ADP1; screened for loss of ability to grow on } 4 \mathrm{HBB}^{\underline{c}}\end{array}$ & [7] \\
\hline ACN472 & $\begin{array}{l}\triangle \text { benD5472 } \\
\text { Deletion of DNA from 1,437,252 to 1,438,007 } 7^{\mathrm{a}} \text { replaced with GCGGCCGC, the recognition } \\
\text { sequence for Notl } \\
\text { PCR fragment X ADP1; screened for loss of ability to grow on benzoate } \underline{\underline{b}}\end{array}$ & Eby [7] \\
\hline ACN2069 & $\begin{array}{l}\triangle g c d:: s a c B-K m^{R} 52069 \\
\text { pBAC1566/Aatll X ADP1; selected by } \mathrm{Km}^{\mathrm{R}}\end{array}$ & This study \\
\hline ACN2070 & $\begin{array}{l}\triangle \text { gcd::sacB-Km }{ }^{R} 52069 ; \triangle \text { pcaHG5462 } \\
\text { pBAC1566/Aatll X ACN462; selected by Km }\end{array}$ & This study \\
\hline ACN2071 & $\begin{array}{l}\triangle g c d:: s a c B-K^{R}{ }^{R} 52069 ; \Delta b e n D 5472 \\
\text { pBAC1566/Aatll X ACN472; selected by } \mathrm{Km}^{\mathrm{R}}\end{array}$ & This study \\
\hline ACN2089 & 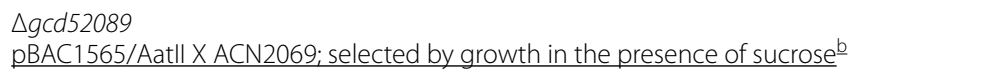 & This study \\
\hline ACN2090 & $\begin{array}{l}\triangle g c d 52089 ; \triangle p c a H G 5462 \\
\text { pBAC1565/Aatll X ACN2070; selected by growth in the presence of sucrose }^{\underline{\underline{b}}}\end{array}$ & This study \\
\hline ACN2091 & $\begin{array}{l}\triangle g c d 52089 ; \triangle \text { benD5472 } \\
\text { pBAC1565/Aatll X ACN2071; selected by growth in the presence of sucrose }{ }^{\underline{b}}\end{array}$ & This study \\
\hline
\end{tabular}

Strains were derived from ADP1, previously known as Acinetobacter calcoaceticus or Acinetobacter sp. [53]

a Italics numbers correspond to positions on the ADP1 chromosome in NCBI entry NC_005966

b Underlined text indicates the donor DNA and, where relevant, the restriction enzyme used to linearize a plasmid (pBAC number/enzyme). The donor DNA was used to transform $(\mathrm{X})$ the indicated recipient strain 
Table 2 Plasmids used in this study

\begin{tabular}{|c|c|c|}
\hline Plasmid & Relevant characteristics & Source \\
\hline pUC18 & $A p^{R}$; cloning vector & Yanisch-Perron et al. [56] \\
\hline pRMJ1 & Source of $s a c B-\mathrm{Km}^{\mathrm{R}}$ cassette & Jones and Williams [17] \\
\hline pCR2.1-TOPO & Vector for cloning PCR products; $A p^{R}, \mathrm{Km}^{R}$ & ThermoFisher (Invitrogen) \\
\hline pBAC890 & $\begin{array}{l}\text { Engineered allele: } \triangle \text { benD } 5472 \\
\text { PCR fragment with this allele was constructed by SOEing (see "Materials and methods"). This fragment was } \\
\text { cloned into pCR2.1-TOPO }\end{array}$ & This study \\
\hline pBAC1565 & $\begin{array}{l}\text { Engineered allele: } \triangle g c d 52089 \\
\text { Carries ADP1 DNA upstream and downstream of the deleted gcd in pUC18; ADP1 region corresponds to } \\
\text { genome positions 2,909,747-2,916,396 with a deletion of 2,911,970 to 2,914,369. The deleted DNA is } \\
\text { replaced by a BamHI recognition sequence (GGATCC) }\end{array}$ & This study \\
\hline pBAC1566 & $\begin{array}{l}\text { Engineered allele: } \triangle g c d:: s a c B-K m^{R} 52069 \\
\text { The sacB-Km }{ }^{R} \text { cassette, excised from pRMJ1 as a BamHI fragment was inserted in the corresponding restric- } \\
\text { tion site of pBAC1565 }\end{array}$ & This study \\
\hline
\end{tabular}

${ }^{a}$ Italics numbers correspond to positions on the ADP1 chromosome in NCBI entry NC_005966

respectively. Unmarked deletion strains, ACN2089, ACN2090, and ACN2091, were generated using strains that carry $s a c B$ as recipients for transformation by linearized pBAC1565. Strains in which the unmarked $g c d$ deletion (allele $\Delta g c d 52089$ ) replaced the corresponding region of the recipient strain were isolated in the presence of sucrose $\left(5 \% \mathrm{w} / \mathrm{v}\right.$ at $\left.30^{\circ} \mathrm{C}\right)$ to select for the loss of $s a c B$.

Two strains with deletions affecting aromatic compound catabolism were previously constructed, ACN462 [7] and ACN472. To generate these strains, an SOEing PCR product was used to transform ADP1. Transformants corresponding to ACN462 and ACN472 were initially identified after screening for the loss of growth on compounds degraded via protocatechuate or benzoate, respectively. The PCR fragment used to generate ACN472 was an SOEing product made with two primers (BenD-Up and BenD-LT) that joined two PCR fragments, one made using BenD-Up with BenD-Del2 and the other made using BenD-Del1 with BenD-LT. A plasmid (pBAC890) that carries DNA of this SOEing product, which has the $\Delta b e n D 5472$ allele, was generated using a TOPO TA cloning kit (ThermoFisher Scientific, Waltham, MA USA).

Kluyveromyces marxianus ATCC 26548 was used without modification. The yeast was routinely grown in YPD medium at $42{ }^{\circ} \mathrm{C}$ and $\mathrm{pH}$ of 5.5 containing $20 \mathrm{~g} / \mathrm{L}$ glucose, $20 \mathrm{~g} / \mathrm{L}$ peptone, and $10 \mathrm{~g} / \mathrm{L}$ yeast extract.

\section{Media and growth conditions}

Defined ADP1 medium was adapted from Shanley et al. [43] and contained (per liter): $3.35 \mathrm{~g} \mathrm{Na}_{2} \mathrm{HPO}_{4} \cdot 7 \mathrm{H}_{2} \mathrm{O}$, $1.70 \mathrm{~g} \mathrm{KH}_{2} \mathrm{PO}_{4}, 1.00 \mathrm{~g}_{\left(\mathrm{NH}_{4}\right)_{2} \mathrm{SO}_{4}, 59 \mathrm{mg} \mathrm{MgSO}} \cdot 7 \mathrm{H}_{2} \mathrm{O}$, $6.7 \mathrm{mg} \mathrm{CaCl}_{2} \cdot 2 \mathrm{H}_{2} \mathrm{O}, 2.2 \mathrm{mg} \mathrm{ZnSO}_{4} \cdot 7 \mathrm{H}_{2} \mathrm{O}, 1.4 \mathrm{mg}$ $\mathrm{FeSO}_{4} \cdot 7 \mathrm{H}_{2} \mathrm{O}, 0.31 \mathrm{mg} \mathrm{MnSO}{ }_{4} \cdot \mathrm{H}_{2} \mathrm{O}, 78 \mu \mathrm{g} \mathrm{CuSO}{ }_{4} \cdot 5 \mathrm{H}_{2} \mathrm{O}$,
$50 \mu \mathrm{g} \mathrm{Co}\left(\mathrm{NO}_{3}\right)_{2} \cdot 6 \mathrm{H}_{2} \mathrm{O}, 35 \mu \mathrm{g} \mathrm{Na} \mathrm{B}_{4} \mathrm{O}_{7} \cdot 10 \mathrm{H}_{2} \mathrm{O}, 19 \mu \mathrm{g}$ $\left(\mathrm{NH}_{4}\right)_{6} \mathrm{Mo}_{7} \mathrm{O}_{24} \cdot 4 \mathrm{H}_{2} \mathrm{O}, 0.5 \mathrm{mg}$ EDTA, and $20 \mathrm{mg}$ nitrilotriacetic acid, and the carbon source sterilized separately. This medium was supplemented with benzoate, $4 \mathrm{HB}$, and/or sugars as described.

\section{Shake flask studies}

In a single strain experiment, cells were first grown in $25 \mathrm{~mL}$ ADP1 medium in $125 \mathrm{~mL}$ baffled shake flasks, and after $24 \mathrm{~h}, 4 \mathrm{~mL}$ was used to inoculate each of triplicate $500 \mathrm{~mL}$ baffled shake flask-containing $100 \mathrm{~mL}$ ADP1 medium, from which measurements were made. In an experiment using two strains (i.e., a consortium), each strain was first grown separately in $25 \mathrm{~mL}$ ADP1 medium as before, and then, $2 \mathrm{~mL}$ from each flask used as inoculum for triplicate $500 \mathrm{~mL}$ shake flasks with $100 \mathrm{~mL}$ ADP1 medium. All flasks nominally contained $2 \mathrm{mM}$ benzoate and $5 \mathrm{mM} 4 \mathrm{HB}$ and were incubated at $37{ }^{\circ} \mathrm{C}$ and $250 \mathrm{rpm}$ (19 mm pitch). The $\mathrm{pH}$ of the medium was 7.0.

\section{Chemostat process}

Continuous degradation of benzoate and $4 \mathrm{HB}$ in the presence of sugars was studied in the chemostat mode at a dilution rate of $0.20 \mathrm{~h}^{-1}$. ACN2069 was first grown in $25 \mathrm{~mL}$ ADP1 medium in $125 \mathrm{~mL}$ shake flasks as described above and after $24 \mathrm{~h}$ transferred to a $2.5 \mathrm{~L}$ bioreactor (Bioflo 2000, New Brunswick Scientific Co., New Brunswick, NJ, USA) containing 1.0 L ADP1 medium. During the process, four different carbon source compositions were supplied using ADP1 medium: From 0 to $24 \mathrm{~h}$ : $2 \mathrm{mM}$ benzoate $/ 5 \mathrm{mM} 4 \mathrm{HB} / 10 \mathrm{mM}$ sugars (i.e., $10 \mathrm{mM}$ glucose, $10 \mathrm{mM}$ xylose, and $10 \mathrm{mM}$ arabinose); from 24 to $48 \mathrm{~h}$ : $5 \mathrm{mM}$ benzoate $/ 5 \mathrm{mM} 4 \mathrm{HB} / 10 \mathrm{mM}$ sugars; from 48 to $72 \mathrm{~h}: 5 \mathrm{mM}$ benzoate/ $10 \mathrm{mM} 4 \mathrm{HB} / 10 \mathrm{mM}$ sugars; 
from 72 to $96 \mathrm{~h}: 2 \mathrm{mM}$ benzoate/10 mM 4HB/10 mM sugars.

\section{Two-stage bacteria-yeast process}

A two-stage biological process was used to detoxify a stream and generate ethanol. In a $2.5 \mathrm{~L}$ vessel containing $1.0 \mathrm{~L}$ of nominally $2 \mathrm{mM}$ benzoate $/ 5 \mathrm{mM} 4 \mathrm{HB}$ and $100 \mathrm{~g} / \mathrm{L}$ glucose in ADP1 medium was inoculated with $25 \mathrm{~mL}$ of ACN2090 and $25 \mathrm{~mL}$ of ACN2091 grown in $125 \mathrm{~mL}$ baffled flasks (as described above). After both aromatic hydrocarbons were depleted, a solution containing $5 \mathrm{mM}$ benzoate $/ 10 \mathrm{mM} 4 \mathrm{HB}$ and $100 \mathrm{~g} / \mathrm{L}$ glucose in ADP1 medium was introduced at $1 \mathrm{~mL} / \mathrm{min}$ for $9 \mathrm{~h}$. Then, the $\mathrm{pH}$ was decreased to 4.3 with sulfuric acid, and over the course of $2 \mathrm{~h}$, the temperature was increased to $55{ }^{\circ} \mathrm{C}$, held for about $1 \mathrm{~h}$, and then decreased to $42{ }^{\circ} \mathrm{C}$ over the course of $0.1 \mathrm{~h}$. After the $\mathrm{pH}$ was increased to 5.2, approximately $2 \mathrm{~g}$ (dry cell basis) of $K$. marxianus in $35 \mathrm{~mL}$ ADP1 medium was used to inoculate the fermenter. After inoculation, air was sparged at $1 \mathrm{~L} / \mathrm{min}$ for $9.3 \mathrm{~h}$ before switching to anaerobic conditions (sparging $\mathrm{N}_{2}$ at $0.1 \mathrm{~L} / \mathrm{min}$ ) for the final $17.5 \mathrm{~h}$.

\section{Analytical methods}

The optical density at $600 \mathrm{~nm}$ (OD) (UV-650 spectrophotometer, Beckman Instruments, San Jose, CA, USA) was used to monitor cell growth. Liquid chromatography using a Coregel 64- $\mathrm{H}$ ion-exclusion column (Transgenomic Ltd., Glasgow, United Kingdom) with a mobile phase of $4 \mathrm{mN} \mathrm{H}_{2} \mathrm{SO}_{4}$ and RI detection was used to quantify all extracellular organic compounds [8].

\section{Additional file}

Additional file 1: Table S1. Primers used in this study.

\section{Authors' contributions}

ELN and MAE conceived the studies and designed the experiments. AS, NKS, SRB, and SAL conducted the experiments. AS, SRB, ELN, and MAE wrote the manuscript. All authors read and approved the final manuscript.

\section{Author details}

${ }^{1}$ Department of Environmental Sciences, Central University of Jammu, Rahya-Suchani, Bagla, India. ${ }^{2}$ School of Chemical, Materials and Biomedical Engineering, University of Georgia, Athens, GA 30602, USA. ${ }^{3}$ Department of Microbiology, University of Georgia, Athens, GA 30602, USA.

\section{Acknowledgements}

The authors thank the Government of India University Grants Commission for sponsorship of Anita Singh as a Raman Post-Doctoral Fellowship, and IndoU.S. Science and Technology Forum for sponsorship of Nilesh K. Sharma as a B-ACER Fellow. The contributions of Melissa Tumen-Velazquez and D. Matthew
Eby are gratefully acknowledged for the construction of pBAC809 and strain ACN472, respectively.

\section{Competing interests}

The authors declare that they have no competing interests.

\section{Availability of data and materials}

All data generated or analyzed during this study are included in this published article.

\section{Ethics approval and consent to participate}

Not applicable.

\section{Funding}

Portions of the research were also funded by NSF Grant DEB-1556541 (to ELN and MAE).

\section{Publisher's Note}

Springer Nature remains neutral with regard to jurisdictional claims in published maps and institutional affiliations.

Received: 13 February 2019 Accepted: 12 April 2019

Published online: 23 April 2019

\section{References}

1. Agblevor FA, Batz S, Trumbo J. Composition and ethanol production potential of cotton gin residues. Appl Biochem Biotechnol. 2003;105-108:219-30.

2. Arora R, Behera S, Sharma NK, Kumar S. A new search for thermotolerant yeasts, its characterization and optimization using response surface methodology for ethanol production. Front Microbiol. 2015;8:889.

3. Beckham GT, Johnson CW, Karp EM, Salvachúa D, Vardon DR. Opportunities and challenges in biological lignin valorization. Curr Opin Biotechnol. 2016;42:40-53.

4. Brzostowicz PC, Reams AB, Clark TJ, Neidle EL. Transcriptional crossregulation of the catechol and protocatechuate branches of the $\beta$-ketoadipate pathway contributes to carbon source-dependent expression of the Acinetobacter sp. strain ADP1 pobA gene. Appl Environ Microbiol. 2003;69(3):1598-606.

5. Crigler J, Bannerman-Akwei L, Cole AE, Eiteman MA, Altman E. Glucose can be transported and utilized in Escherichia coli by an altered or overproduced $\mathrm{N}$-acetylglucosamine phosphotransferase system (PTS). Microbiology. 2018;164:163-72.

6. Davis R, Biddy M, Tan E, Tao L. Biological conversion of sugars to hydrocarbons technology pathway, NREL/PNNL technical report \# NREL/TP-510058054. Golden CO: National Renewable Energy Laboratory; 2013.

7. Eby DM. Genetic and biochemical studies of aromatic dioxygenase substrate specificity in Acinetobacter sp. strain ADP1. Doctoral dissertation, University of Georgia. 2002

8. Eiteman MA, Chastain M. Optimization of the ion-exchange analysis of organic acids from fermentation. Anal Chim Acta. 1997;338(1):69-75.

9. Eiteman MA, Lee SA, Altman E. A co-fermentation strategy to consume sugar mixtures effectively. J Biol Eng. 2008;2:3.

10. Elliot KT, Neidle EL. Acinetobacter baylyi ADP1: transforming the choice of model organism. IUBMB Life. 2011;63(12):1075-80.

11. Gámez S, González-Cabriales JJ, Ramírez JA, Garrote G, Vázquez M. Study of the hydrolysis of sugar cane bagasse using phosphoric acid. J Food Eng. 2006;74:78-88.

12. Hamelinck CN, van Hooijdonk G, Faaij APC. Ethanol from lignocellulosic biomass: techno-economic performance in short-, middle-, and longterm. Biomass Bioenergy. 2005;28:384-410.

13. Harder W, Dijkhuizen L, Postgate JR. Strategies of mixed substrate utilization in microorganisms. Phil Trans R Soc London B. 1982;297(1088):459-80.

14. Heer D, Sauer U. Identification of furfural as a key toxin in lignocellulosic hydrolysate and evolution of a tolerant yeast strain. Microbial Biotechnol. 2008;1(6):497-506. 
15. Horton RM, Cai ZL, Ho SN, Pease LR. Gene splicing by overlap extension: tailor-made genes using the polymerase chain reaction. Biotechniques. 1990;8:528-35.

16. Huber GW, Iborra S, Corma A. Synthesis of transportation fuels from biomass: chemistry, catalysis, and engineering. Chem Rev. 2006;106:4044-98.

17. Jones RM, Williams PA. Mutational analysis of the critical bases involved in activation of the AreR-regulated $\sigma^{54}$-dependent promoter in Acinetobacter sp. strain ADP1. Appl Environ Microbiol. 2003;69:5627-35.

18. Jönsson LJ, Palmqvist E, Nilvebrant NO, Hahn-Hägerdal B. Detoxification of wood hydrolysates with laccase and peroxidase from the white-rot fungus Trametes versicolor. Appl Microbiol Biotechnol. 1998:49:691-7.

19. Juni E, Janik A. Transformation of Acinetobacter calcoaceticus (Bacterium anitratum). J Bacteriol. 1969;98:281-8.

20. Kadam KL, McMillan JD. Availability of corn stover as a sustainable feedstock for bioethanol production. Bioresour Technol. 2003;88:17-25.

21. Kannisto MS, Mangayil RK, Shrivastava-Bhattacharya A, Pletschke BI, Karp MT, Santala VP. Metabolic engineering of Acinetobacter baylyi ADP1 for removal of Clostridium butyricum growth inhibitors produced from lignocellulosic hydrolysates. Biotechnol Biofuels. 2015;8:198.

22. Karp EM, Nimlos CT, Deutch S, Salvachúa D, Cywar RM, Beckham GT. Quantification of acidic compounds in complex biomass-derived streams. Green Chem. 2016;18:4750-60.

23. Kim S, Dale BE. Global potential bioethanol production from wasted crops and crop residues. Biomass Bioenergy. 2004;26:361-75.

24. Kumar S, Singh SP, Mishra IM, Adhikari DK. Feasibility of ethanol production with enhanced sugar concentration in bagasse hydrolysate at high temperature using Kluveromyces marxianus sp. IIPE453. Biofuels. 2010;1:697-704.

25. Lawford HG, Rousseau JD. Effects of acetic acid on glucose and xylose metabolism by a genetically engineered ethanologenic Escherichia coli. Appl Biochem Biotechnol. 1993;39:301-22.

26. Maleki N, Safari M, Eiteman MA. Conversion of glucose-xylose mixtures to pyruvate using a consortium of metabolically engineered Escherichia coli. Eng Life Sci. 2018;18:40-7.

27. Martinez A, Rodriguez ME, Wells ML, York SW, Preston JF, Ingram LO. Detoxification of dilute acid hydrolysates of lignocellulose with lime. Biotechnol Prog. 2001;17:287-93.

28. Martín C, Marcet M, Almazín O, Jönsson LJ. Adaptation of a recombinant xylose-utilizing Saccharomyces cerevisiae strain to a sugarcane bagasse hydrolysate with high content of fermentation inhibitors. Bioresour Technol. 2007;98(9):1767-73.

29. Moreno AD, Ibarra D, Alvira P, Tomás-Pejó E, Ballesteros M. A review of biological delignification and detoxification methods for lignocellulosic bioethanol production. Crit Rev Biotechnol. 2015;35(3):342-54.

30. Mussatto SI, Roberto IC. Alternatives for detoxification of diluted-acid lignocellulosic hydrolysates for use in fermentative processes: a review. Bioresour Technol. 2004;93(1):1-10.

31. Narendranath NV, Thomas KC, Ingledew WM. Acetic acid and lactic acid inhibition of growth of Saccharomyces cerevisiae by different mechanisms. J Am Soc Brew Chem. 2001;59:187-94.

32. Neidle EL, Hartnett C, Ornston LN. Characterization of Acinetobacter calcoaceticus catM, a repressor gene homologous in sequence to transcriptional activator genes. J Bacteriol. 1989;171:5410-21.

33. Nichols NN, Dien BS, Cotta MA. Fermentation of bioenergy crops into ethanol using biological abatement for removal of inhibitors. Bioresour Technol. 2010;101:7545-50.

34. Nilvebrant NO, Reimann A, Larsson S, Jönsson LJ. Detoxification of lignocellulose hydrolysates with ion exchange resins. Appl Biochem Biotechnol. 2001;91-93:35-49.

35. Parajó JC, Domínguez H, Domínguez JM. Charcoal adsorption of wood hydrolysates for improving their fermentability: influence of the operational conditions. Bioresour Technol. 1996;57:179-85.

36. Perlack RD, Stokes BJ. U.S. Billion-Ton Update: biomass supply for a bioenergy and bioproducts industry. Oak Ridge: U.S. Department of Energy, Oak Ridge National Laboratory; 2011.

37. Rodrussamee N, Lertwattanasakul N, Hirate K, Suprayogi, Limtong S, Kosaka T, Yamada M. Growth and ethanol fermentation ability on hexose and pentose sugars and glucose effect under various conditions in thermotolerant years Kluyveromyces marxianus. Appl Microbiol Biotechnol. 2011;90:1573-86.

38. Roe AJ, McLaggan D, Davidson I, O'Bryne C, Booth IR. Perturbation of anion balance during inhibition of growth of Escherichia coli by weak acids. J Bacteriol. 1998;180:767-72.

39. Saini JK, Saini R, Tewari L. Lignocelluosic agriculture wastes as biomass feedstocks for second-generation bioethanol production: concepts and recent developments. 3 Biotech. 2015;5:337-53.

40. Salvachúa D, Karp EM, Nimlos CT, Vardon DR, Beckham GT. Towards lignin consolidated bioprocessing: simultaneous lignin depolymerization and product generation by bacteria. Green Chem. 2015;17:4951-67.

41. Sarkar N, Ghosh SK, Bannerjee S, Aikat K. Bioethanol production from agricultural wastes: an overview. Renewable Energy. 2012;26:361-75.

42. Sene L, Converti A, Zilli M, Felipe MGA, Silva SS. Metabolic study of the adaptation of the yeast Candida guilliermondii to sugar cane bagasse hydrolysate. Appl Microbiol Biotechnol. 2001;57:738-43.

43. Shanley MS, Neidle EL, Parales RE, Ornston LN. Cloning and expression of Acinetobacter calcoaceticus catBCDE genes in Pseudomonas putida and Escherichia coli. J Bacteriol. 1986;165(2):557-63.

44. Silva CJSM, Roberto IC. Improvement of xylitol production by Candida guilliermondii FTI 20037 previously adapted to rice straw hemicellulosic hydrolysate. Lett Appl Microbiol. 2001;32:248-52.

45. Taha M, Foda M, Shahsavari E, Aburto-Medina A, Adetutu E, Ball A. Commaercial feasibility of lignocellulose biodegradation: possibilities and challenges. Curr Opin Biotechnol. 2016;38:190-7.

46. Taylor WH, Juni E. Pathways for biosynthesis of a bacterial capsular polysaccharide. II. Carbohydrate metabolism and terminal oxidation mechanisms of a capsule-produce coccus. J Bacteriol. 1961;81:694-703.

47. Templeton DW, Sluiter AD, Hayward TK, Hames BR, Thomas SR. Assessing corn stover composition and sources of variability via NIRS. Cellulose. 2009;16:621-39.

48. Thomas KC, Hynes SH, Ingledew WM. Influence of medium buffering capacity on inhibition of Saccharomyces cerevisiae growth by acetic and lactic acids. Appl Environ Microbiol. 2002;68:1616-23.

49. Tran AV, Chambers RP. Red oak wood derived inhibitors in the ethanol fermentation of xylose by Pichia stipitis CBS 5776. Biotechnol Lett. 1985;7:841-6.

50. Tran AV, Chambers RP. Lignin and extractives derived inhibitors in the 2,3-butanediol fermentation of mannose-rich prehydrolysates. Appl Microbiol Biotechnol. 1986;23:191-7.

51. Tumen-Velasquez $M$, Johnson CW, Ahmed A, Dominick D, Fulk E, Khanna P, Lee SA, Schmidt AL, Linger JG, Eiteman MA, Beckham GT, Neidle EL. Accelerating pathway evolution by increasing the gene dosage of chromosomal segments. Proc Natl Acad Sci USA. 2018;115:7105-10.

52. U.S. Department of Energy. Office of Energy Efficiency and Renewable Energy. U.S. Billion-Ton Update: biomass supply for a bioenergy and bioproducts industry. 2011.

53. Vaneechoutte M, Young DM, Ornston LN, DeBaere T, Nemec A, Van Der Reijden T, Carr E, Tjernberg I, Dijkshoorn L. Naturally transformable Acinetobacter sp. strain ADP1 belongs to the newly described species Acinetobacter baylyi. App Environ Microbiol. 2006;72:932-6.

54. Wael S, Dietz D, Tjahjasari D, Zeng AP. Biosystems analysis and engineering of microbial consortia for industrial biotechnology. Eng Life Sci. 2010;10:407-21.

55. Xia T, Eiteman MA, Altman E. Simultaneous utilization of glucose, xylose and arabinose in the presence of acetate by a consortium of Escherichia coli strains. Microb Cell Fact. 2012;11:77.

56. Yanisch-Perron C, Vieira J, Messing J. Improved M13 phage cloning vectors and host strains: nucleotide sequences of the M13mpl8 and pUC19 vectors. Gene. 1985;33:103-19.

57. Young DM, Parke D, Ornston LN. Opportunities for genetic investigation afforded by Acinetobacter baylyi, a nutritionally versatile bacterial species that is highly competent for natural transformation. Annu Rev Microbiol. 2005;59:519-51.

58. Yu Y, Feng $Y, X u$ C, Liu J, Li D. Onsite bio-detoxification of steam exploded corn stover for cellulosic ethanol production. Bioresour Technol. 2011;102:5123-8.

59. Zhang J, Zhu Z, Wang X, Wang N, Wang W, Bao J. Biodetoxification of toxins generated from lignocellulose pretreatment using a newly isolated fungus, Amorphotheca resinae ZN1, and the consequent ethanol fermentation. Biotechnol Biofuels. 2010;3:26. 